\title{
Integration of Carbon Nanotubes in Microelectronics
}

\author{
Stanislav A. Moshkalev ${ }^{1}$, Carla Veríssimoㄹ, Rogério V. Gelamo, \\ Leonardo R. C. Fonseca ${ }^{2}$, Ettore Baldini-Neto ${ }^{2}$ and Jacobus W. Swart ${ }^{3}$ \\ ${ }^{1}$ State University of Campinas-UNICAMP, Campinas, SP, \\ ${ }^{2}$ Center of Advanced Research W. von Braun, Campinas, $S P$, \\ ${ }^{3}$ Center for Information Technology Renato Archer-CTI, Campinas, SP, \\ Brazil
}

\section{Introduction}

Carbon nanotubes (CNTs) has received much attention since their discovery in 1991 due to unique combination of interesting electrical, mechanical, thermal and other properties, and numerous potential applications (Meyyappan, 2005, Sharma, 2008). Single-wall carbon nanotubes (SWCNTs) can be metallic or semiconducting, while multi-wall nanotubes (MWCNTs) are basically metallic. Semiconducting SWCNTs can be used in nanotubes based field effect transistors (FET-CNT), while metallic SWCNTs and MWCNTs can be employed for electrical and thermal interconnections, in sensors and other micro- and nanodevices. However, the integration of nanotubes into microelectronic circuitry is a very challenging task which requires development of reliable and compatible technologies for controlled synthesis, accurate positioning and contacting of nanotubes and their arrays in new devices. Many difficult issues associated with these technologies have to be addressed. In particular, mechanisms of nucleation and growth of high quality nanotubes still are not well understood. Mechanisms of electrical and thermal conductivity in individual nanotubes and ropes, the role of defects, formation of contacts with metals have to be investigated thoroughly.

\section{Electrical properties of carbon nanotubes}

SWCNT can be viewed as a single graphite (or graphene) sheet rolled into a cylinder of a nanometer size diameter, and MWCNT as a coaxial array of several single-wall nanotubes separated by approximately $0.34 \mathrm{~nm}$. In graphene layers, $\mathrm{sp}^{2}$ hybridyzation results in formation of three strong in-plane $\sigma$ bonds between carbon atoms and one $\pi$ bond, the latter corresponding to loosely bound $\pi$ electrons of high mobility that are responsible for a very high conductivity along the graphene plane.

As SWCNTs are essentially one-dimensional structures, at the absence of defects they are characterized by a ballistic transport of electrons (without scattering) at moderate current densities for nanotube lengths up to a few micrometers (Graham et al, 2004). This is in striking contrast to metal (copper) wires where the mean free pass (MFP), determined by the mean grain size, is in the range of a few tens of nanometers.

Source: Solid State Circuits Technologies, Book edited by: Jacobus W. Swart,

ISBN 978-953-307-045-2, pp. 462, January 2010, INTECH, Croatia, downloaded from SCIYO.COM 
Another advantage of nanotubes is that small diameter copper vias are subject to failure due to electromigration at high current densities $\left(>10^{6} \mathrm{~A} / \mathrm{cm}^{2}\right)$ while CNTs of the same diameter can sustain current densities as high as $10^{9} \mathrm{~A} / \mathrm{cm}^{2}$ (Graham et al, 2004). This makes CNTs very attractive for electrical interconnect applications (especially, vias) instead of currently used copper.

The resistance of a SWCNT (or a shell in a MWCNT) has three components (Tan et al, 2007; Matsuda et al, 2007): (i) a contact resistance associated with one-dimensional systems, given by a quantum resistance $\mathrm{G}_{0}^{-1}=\mathrm{h} / 2 \mathrm{e}^{2}=12.9 \mathrm{k} \Omega$ corresponding to one conducting state (a factor of two is added due to two possible spin states), (ii) an intrinscic resistance due to scattering which is length dependent, and (iii) an additional contact resistance associated with imperfect contacts between a metal electrode and CNTs. Metals that form carbides (e.g., Ti) are believed to be an optimal electrode material as it is expected that carbides ensure better electrical coupling with nanotubes (Tan et al, 2007).

It is very challenging to evaluate precisely the contribution of contact resistances due to evident experimental difficulties. Comparison between different experiments is also not straightforward because of wide variation of conditions and particular geometries used for studies (for example, side- and end- contacts, presence of surfactants and other contaminants, metal grain sizes and degree of metal annealing after its deposition over nanotubes, etc.). SWCNTs can be metallic or semiconducting, depending on chirality. The energy gap for semiconducting nanotubes is given aproximately by $E_{g}(e V)=1 / d(n m)$, reducing rapidly with the graphene shell diameter $d$. Usually, the number of metallic SWCNTs in as-grown samples is close to $1 / 3$, the rest are semiconducting. In contrast, MWCNTs of larger diameters are basically metallic and thus are especially appropriate for interconnects.

The number of conducting states per graphene shell depends on its chirality, it can be 0 or 2 for small diameter semiconducting and metallic SWCNTs, respectively, and it increases linearly with the shell diameter for larger nanotubes (Naeemi and Meindl, 2007). MFP also was shown to increase with MWCNT diameter. The theoretical limit for resistance of highquality MWCNTs (diameter of $15 \mathrm{~nm}, 10$ walls) in a ballistic regime can be lower than 0.1 $\mathrm{k} \Omega$ (for lengths smaller than MFP), compared with the resistance of about $1 \mathrm{k} \Omega$ for a $150 \mathrm{~nm}$ long, $10 \mathrm{~nm}$ diameter copper damascene wire (Graham et al, 2004). The model of MWCNTs as electrical conductors developed by Naeemi and Meindl, 2007, predicts that they can outperform copper wires for lengths exceeding 5-10 $\mu \mathrm{m}$, depending on diameter. Bundles of SWCNTs were shown to have potentially superior performance at smaller leghths $(<1 \mu \mathrm{m})$, however for this, dense nanotube packing is essencial which is a very difficult practical task. Recently, it has been reported by Jun et al, 2007, that the AC conductance of high quality PECVD (plasma enhanced chemical vapor deposition) grown MWCNTs decreases gradually with increasing frequency (frequencies up to $50 \mathrm{GHz}$ were studied), indicating that nanotubes can be used not only for DC but also in a microwave range.

\section{Synthesis of carbon nanotubes}

It is important to emphasize that properties and quality of carbon nanotubes depend strongly on the fabrication method. There are two main groups of CNTs synthesis methods: (i) high-temperature processes like arc discharge and laser evaporation where the process temperature can reach $\mathrm{T}=2000-4000^{\circ} \mathrm{C}$, and (ii) chemical vapor deposition (CVD) processes 
performed at much lower temperatures: in the range of $500-1000{ }^{\circ} \mathrm{C}$ for thermal CVD and even lower for plasma-enhanced CVD. In high-temperature processes, higher quality nanotubes can be obtained, however the process output is a CNT containing soot which needs to be further processed (dispersed, purified and in some cases functionalized) before applications. The low-temperature CVD methods can be compatible with microelectronic technologies and therefore attract most attention. Note that activation by plasmas in PECVD processes can promote formation of higher quality nanotubes at lower temperatures, and thus PE-CVD is a promissing technology for microelectronics applications. Electric fields built-up in the plasma, can also be used to provide directional nanotube growth. Studies of nucleation mechanisms (Moshkalev \& Veríssimo, 2007) and search for new methods of synthesis, compatible with microelectronics technologies, must continue to provide better control on the properties, location, growth direction and quality of nanotubes.

\section{Measurements of CNT resistances}

Experimental measurements of individual nanotube resistances can be performed using 2or 4-points methods. To deposit nanotubes over pre-fabricated metal electrodes, an AC dielectrophoresis (DEP) method (Krupke et al, 2007; Vaz et al, 2008) can be applied, see Fig. 1a. As contact resistances obtained after DEP are frequently very high, further improvement of CNT-electrode contacts using metal (e.g., Ni or Pd) deposition by electroless methods, usually followed by annealing, is required (Vaz et al, 2008; Liebau et al, 2003). For 4-points measurements, additional electrodes can be made using platinum $(\mathrm{Pt})$ deposition induced by focused ion or electron beams, see example in Fig. 1b.
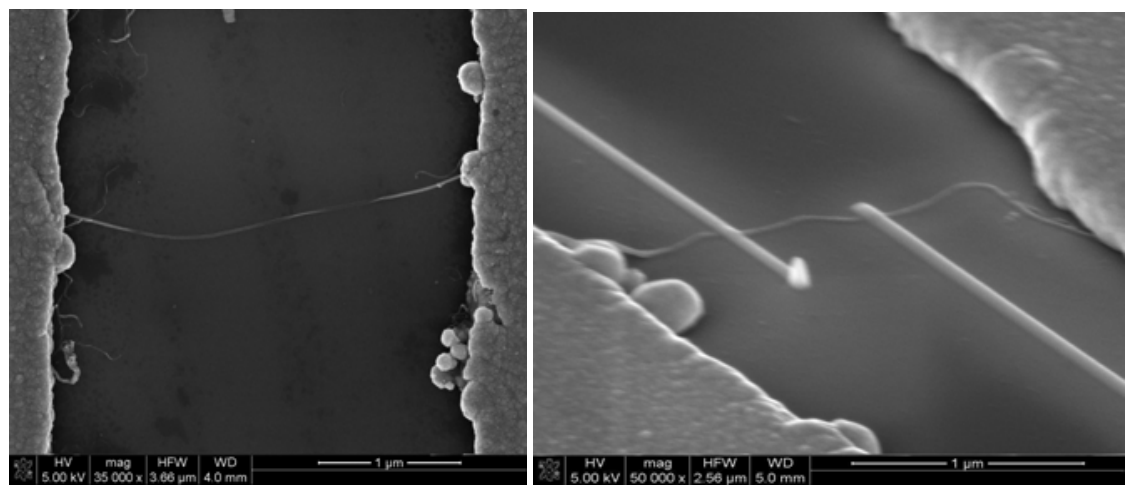

Fig. 1. (a) Individual MWCNT deposited by AC dielectrophoresis over Pd electrodes and then cover by Ni electroless process. (b) For 4-points measurements, 2 intermediate Pt electrodes are fabricated by electron beam induced deposition.

For MWCNTs grown by CVD (15 nm diameter), typical resistances of $\sim 40 \mathrm{k} \Omega / \mu \mathrm{m}$ were measured, while resistances of electroless deposited Ni contacts were estimated to be $\sim 10$ $\mathrm{k} \Omega$ per contact (Liebau et al, 2003). In another work, for PE-CVD grown MWCNTs $(25 \mathrm{~nm}$ diameter, $5 \mu \mathrm{m}$ long) considerably lower resistances $(<10 \mathrm{k} \Omega / \mu \mathrm{m})$ were measured using a 2point method and $\mathrm{Nb}$ electrodes deposited by evaporation (contact resistances were not estimated) (Jun et al, 2007). In our studies (Moshkalev et al, 2008), similar values were obtained for low-bias contact resistances using CVD grown MWCNTs (30 nm mean 
diameter): $\sim 20 \mathrm{k} \Omega$ per $\mathrm{Pd}$ or Ni electroless contacts. It should be noted that distinctly different values of MWCNT resistances were obtained for relatively short MWCNTs (nanotube lengths $<1 \mu \mathrm{m}$ ) using 2 and 4 points methods: $\sim 30 \mathrm{k} \Omega / \mu \mathrm{m}$ and $100 \mathrm{k} \Omega / \mu \mathrm{m}$, respectively. This was attributed to different contact geometries: in the former, all-around contacts were formed during electroless metal deposition over nanotubes, while in the latter, nanotubes were only side-contacted thus the contribution of internal shells to the measured conductance was considerably smaller. This finding emphasizes the importance of careful evaluation of the measurement conditions, particularly in terms of nanotube/metal contacting.
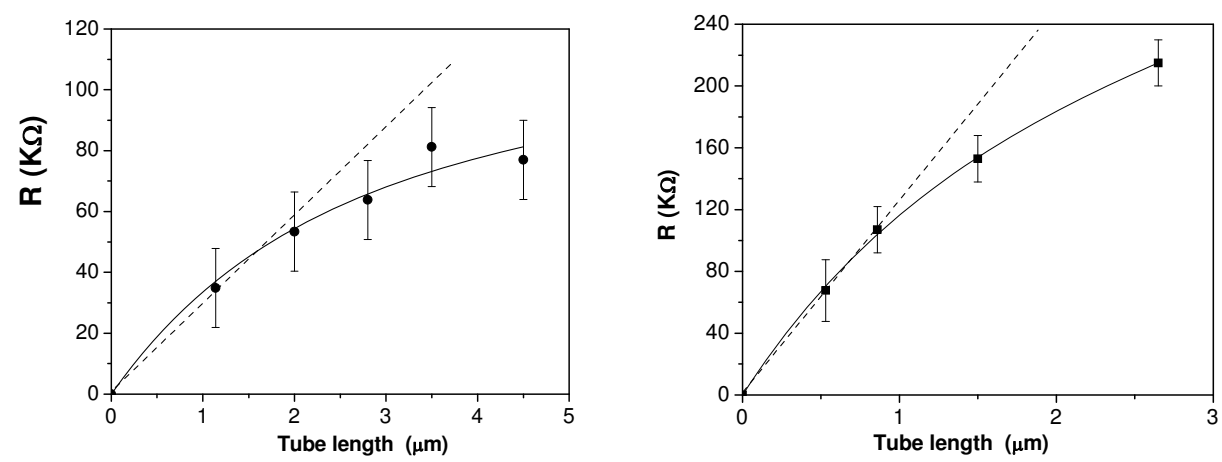

Fig. 2. Left: Two-points resistance vs. nanotube length (the contact resistance subtracted), solid line - fitting to the model, dashed line - linear approximation. Right: Four-points resistance vs. nanotube length, solid line - fitting to the model, dashed line - linear approximation.

More detailed studies of the MWCNT resistance as function of nanotube length (Moshkalev et al, 2008) have shown a non-linear behavior for tubes longer than 1-2 $\mu \mathrm{m}$, in both 2 and 4 points measurements (Fig. 2). This is likely due to increasing conduction to internal walls as tube length grows. The data can be interpreted using the model of a nanotube as a resistive transmission line consisting of two parallel linear conductors (Bourlon et al, 2004). From the model, one can evaluate the resistance of an external shell $\rho_{1}$, of internal shell $\rho_{2}$ (only two outermost shells are considered in the model) and the intershell conductance $g$. For MWCNTs produced by arc discharge method, characteristic values $\rho_{1} \sim 10 \mathrm{k} \Omega / \mu \mathrm{m}, \rho_{2} \sim 0.1$ $x \rho_{1}$ and $g=(10 \mathrm{k} \Omega)^{-1} / \mu \mathrm{m}$ were obtained by fitting using the model (Bourlon et al, 2004).

In our study for CVD grown MWCNTs, the following data were obtained, using 2 and 4 points configurations:

i. 2-points, $\mathrm{Pd}$ all-around contacted nanotubes (Fig. 2, left): $\rho_{1} \sim 37 \mathrm{k} \Omega / \mu \mathrm{m}, \rho_{2} \sim 4$ $\mathrm{k} \Omega / \mu \mathrm{m}, \mathrm{g} \sim(100 \mathrm{k} \Omega)^{-1} / \mu \mathrm{m}$;

ii. 4-points, side-contacted nanotubes (Fig. 2, right): $\rho_{1} \sim 100 \mathrm{k} \Omega / \mu \mathrm{m}, \rho_{2} \sim 22 \mathrm{k} \Omega / \mu \mathrm{m}, \mathrm{g} \sim$ $(100 \mathrm{k} \Omega)^{-1} / \mu \mathrm{m}$.

As discussed above, the difference in measured resistances can be explaned by different contact geometries.

The data presented show that resistances of MWCNTs produced by different methods are still far from theoretical limits and thus are not yet suitable for interconnect apllications in 
microelectronics. Better quality (lower resistance) is characteristic of nanotubes produced by high-temperature (arc, laser) methods compared with a conventional thermal CVD. Further optimization of growth and contacting tecnologies aiming to obtain lower nanotube resistances and better contacts (in particular, direct contact to internal walls) is strongly required.

\section{Contacts of nanotubes with metals: theoretical and experimental approaches}

At the most fundamental level, the resistance of a metal contact to a nanotube requires a calculation of the quantum mechanical transmission between the two objects (Lan et al, 2008). Such theories usually assume an ideal interface between a nanotube and the metal contact, which in practice is frequently contaminated with different impurities.

For calculations, usually the interface between graphene (flat graphitic monolayer) and metal is considered. Graphene, the building block for other graphitic materials such as the 3D graphite (stacked graphene planes), 1D carbon nanotubes (rolled graphene sheets), and 0D carbon buckyballs (wrapped graphene specks), consists of a flat monolayer of carbon atoms tightly packed in a two-dimensional honeycomb lattice. It is important to note that despite long known in the literature, with the electronic structure of graphite well established since the 40's, it was the groundbreaking article of Novoselov et al., 2004, which brought up interest in graphene as a potential material for a number of applications. One of important applications is in microelectronics, where graphenes (in a form of nanotubes and, more recently, of few-layer graphites or FLG) with their highly unusual properties deriving from its two-dimensional geometry open new opportunities. Since then graphene has been intensively investigated both theoretically and experimentally as reviewed by Geim \& Novoselov, 2007. Several experimental groups have focused on new field effect transistors where silicon is replaced by graphene as the channel material (Novoselov et al, 2004; Wang et al, 2008). These devices take advantage of graphene's high and nearly temperature independent mobility of carriers leading to ballistic transport in the submicrometer scale, its linear I x V characteristics, and its unusually large sustainable currents $\left(>10^{8} \mathrm{~A} / \mathrm{cm}^{2}\right)$. To create a graphene-based transistor, graphene is typically deposited over some substrate, usually $\mathrm{SiO}_{2}$ (Ishigami et al, 2007), or grown on top of some carbon-based substrate such as $\mathrm{SiC}$ (Berger et al, 2004). Because the substrate may alter graphenes electronic properties, these groups have investigated if and how this interaction happens, and the impact it causes (Akcoltekin et al, 2009).

Theoretical studies of single- and multi-layer graphene have employed the tight binding model which describes their band structures through the Dirac formalism (Castro Neto et al, 2009). In the presence of other chemical species such as dopants or adsorbates, or for graphene on substrates, under gate dielectrics, or on/under metal contacts, graphene may be structurally and/or electronically affected depending on the nature of the species involved. In this context, many-body effects such as electronic exchange and correlations may play an important role in describing correctly the band structure, requiring ab initio techniques for the simulation of such systems.

Density functional theory (DFT) is particularly suitable to simulate large systems, which is typical of graphene/substrate interface models (Zhou et al, 2007). DFT has been employed to investigate the interaction of graphene with metal contacts (Chan et al, 2008; Giovannetti et al, 2008; Ran et al, 2009) and other substrates. In the specific case of metal-graphene 
contacts it is important to understand how the two materials interact at the interface, since this information will help to optimize device operation. For example, a large electrical contact resistance degrades device performance. Because good contacts are usually formed under chemical interaction, knowing the bond strength at these interfaces is crucial to the comprehension of the device transport characteristics. Here we mention the results of Chan et al., 2008, obtained with first principles DFT within the generalized gradient approximation (GGA), which show that ionic bonds are formed between graphene and metals from groups I-III, while covalent bonds are formed between graphene and transitional, noble, and group IV metals. Another study by Giovanetti et al, 2008, found that metal/graphene contacts can be divided in two groups ( $p$ and $n$ ) by observing the Fermi level change with respect to the Dirac point in the band structure. In a more recent study, Ran et al., 2009, claim, also based on first principles DFT calculations, that there exist two groups of metal/graphene contacts depending on the strength of the interaction between $\mathrm{d}$ orbitals in metals and $p_{z}$ orbitals in graphene.

In the first group (typical example: Ti) strong chemically bonded contacts are formed through the attractive interactions between the $3 \mathrm{~d}$ electrons of the metal and the $\mathrm{p}_{\mathrm{z}}$ states in graphene, while the second group (example: Au) comprises of weak physically bonded contacts. Both situations are essentially determined by the electronic configurations of the metals. The authors also perform transport simulations and their results suggest that metals which form chemical contact with graphene might be best as electrode materials in graphene-based electronics.

Resuming, theoretical studies have indicated that $\mathrm{Ti}$ contacts have lower resistances followed by $\mathrm{Pd}, \mathrm{Pt}, \mathrm{Cu}$ and $\mathrm{Au}$ (Matsuda et al, 2007), basically confirming the experimentally observed trends. However, it should be noted that the high reactivity of $\mathrm{Ti}$ may lead to its oxidation and distortion of a nanotube structure in the contact region.

Finally, theoretical simulations involving single- and multi-layer graphene in contact with different materials are an important tool to investigate these systems, helping to pave the way for the next generation of electronic devices.

In practice, determining the contact resistance is usually a very difficult task, and requires a great number of experiments to give statistically averaged results. An interesting approach to measure the contact properties between an individual multi-wall nanotube and thin metal layer has been recently developed by Lan et al, 2008. For this, sequential cuts by a focused ion beam (beam diameter of $\sim 10 \mathrm{~nm}$ ) in the area of contact (reducing the contact length) were utilized. Then, from the measured dependence of 2-terminal resistance on the contact length, both specific nanotube resistance and contact resistance can be evaluated. For PECVD grown MWCNTs with diameters in the range of 50-60 nm and thin Ag metal film deposited by evaporation, following parameters were obtained: 1) nanotube resistances $4.5 \mathrm{k} \Omega / \mu \mathrm{m}, 2)$ specific contact resistances $r_{\mathrm{c}}$ were shown to depend strongly on the thickness of the Ag film, being of $38 \mathrm{k} \Omega \mu \mathrm{m}$ and $1.6 \mathrm{k} \Omega \mu \mathrm{m}$ (i.e., $6.4 \mathrm{k} \Omega$ for 2 contacts of $0.5 \mu \mathrm{m}$ length each) for Ag layers of 23 and $63 \mathrm{~nm}$, respectively. From the relation $r_{\mathrm{c}}=\rho_{\mathrm{c}} /(\pi \mathrm{d} / 2)$, where $\rho_{\mathrm{c}}$ is the specific contact resistivity for a nanotube of diameter $d, \rho_{\mathrm{c}}$ values were determined: 35 and $1.3 \mu \Omega \mathrm{cm}^{2}$, for 23 and $63 \mathrm{~nm}$ thick layers of $\mathrm{Ag}$, respectively. In this case, the contribution of contact resistances (inversely proportional to its length) to a total 2 terminal resistance becomes insignificant for contact lengths exceeding $1 \mu \mathrm{m}$. Much higher values for thinner metal films are due to non-complete coverage of the nanotubes. 
Note that in the measurements using the transfer length method (TLM) by Jackson \& Graham, 2009, the specific contact resistance between a thin film single wall carbon nanotube electrode and a deposited silver contact were found to be considerably higher: 20 $\mathrm{m} \Omega \mathrm{cm}^{2}$. The same method was used by Liu et al, 2008, but the test structures for TLM were produced using densified carbon nanotube strips formed from vertically-aligned CNT forests and various metal films. Contact resistances of Ti/CNT, Pd/CNT, Ta/CNT, and W/CNT contacts with the same nominal contact area were extracted to be 40,49, 108, and $160 \Omega$, respectively. This corresponds to even higher specific contact resistivity values for the nominal contact area $\sim 0.144 \mathrm{~mm}^{2}$. The high resistivity is explained by the geometry of the experiments, where intertube tunneling is the main mechanism of lateral conduction. It is also argued that actual metal/CNT contact area can be much smaller than the nominal contcat area, so that $\rho_{\mathrm{c}}$ values cannot be accurately calculated. These results show that much care should be taken while comparing data obtained using different methods and specific experimental conditions. Speaking more generally, considerable contributions still should be developed in the area of metrology of measurements involving nanostructured materials, in particular nanotubes.

\section{MWCNTs for sensing applications}

Another interesting appilcation of carbon nanotubes is for gas sensing (Star et al, 2006; Zhao, et al, 2007). However, bare nanotubes do not show appreciable sensitivity to some gases, and recently demonstrated decoration of CNTs by nanoparticles (NPs) (Kong et al, 2001) sensitive to the gases of interest (electron-donating or electron-withdrawing) opened the way to CNT/NP based gas sensors with improved performance and wider area of applications. CNT/NP hybrid nanostructures can be selectively sensitive towards various species in a gas or vapor. Nanoparticles of metals like $\mathrm{Pd}, \mathrm{Al}, \mathrm{Pt}, \mathrm{Sn}, \mathrm{Pd}$ and $\mathrm{Rh}$ have been used to decorate CNTs, allowing selective detection of gases like $\mathrm{H}_{2}, \mathrm{NH}_{3}, \mathrm{NO}_{2}$ (Kim et al, 2006), $\mathrm{CH}_{4}$ (Lu et al, 2004), $\mathrm{H}_{2} \mathrm{~S}$ and $\mathrm{CO}$ (Star et al, 2006). CNT/NP based gas sensors in different configurations (e.g., CNT-FET, chemical resistors) can have extremely high selectivilty due to high aspect ratio, fast time response and extremely low power consumption ( $\mu \mathrm{W}$ range). Currently, considerable research efforts are concentrated on development of technologies (among them: electroless, sputtering, reflux, hydrolysis, supercritical $\mathrm{CO}_{2}$ and others) capable to decorate both SWCNTs and MWCNTs with different metals and their oxides, selectively sensitive to different gases.

Other nanostructured materials, metal oxide nanowires (NWs) have been recently implemented as gas sensing elements with high surface-to-volume ratios that allow for considerable improvement of sensitivity and reduction of response/recovery times and power consumption (to $\sim 10^{-5} \mathrm{~W}$, at typical bias of 5-10 V) (Kolmakov and Moskovits, 2004). Furthemore, in experiments with $\mathrm{SnO}_{2}$ NWs, self-heating by Joule effect has been shown to provide local NW temperatures high enough $\left(\sim 200-300{ }^{\circ} \mathrm{C}\right.$, Prades et al, 2008) to avoid the use of external heating in gas sensing experiments. Note that an external heating (and high power consumption) is usually required for conventional sensors based on metal oxide thin films. However, two functions, sensing and self-heating, are coupled in the same element: the NW resistance can be changed significantly under exposure to the gas, in turn this will change the power dissipated on a NW and thus its temperature. This may result in nonlinearities in the sensor response and requires appropriate calibration procedures. 
CNT/NP hybrid structures represent other alternative of nano-scaled gas sensors that can operate at low voltage and power consumption (Gelamo et al, 2009). Depending on the type of nanotube, basically two different sensor configurations are currently under intensive studies: field effect transistors (FETs) and chemiresistors (CRs). FETs using semiconducting single-wall carbon nanotubes, have shown to be very sensitive to various gases however fabrication of these devices is technologically more challenging than those based on CRs. Thin films of mixed metallic and semiconducting SWCNTs deposited between arrays of interdigitated electrodes in a CR configuration, were shown to be very sensitive to gases like $\mathrm{NO}_{2}$ and $\mathrm{CH}_{4}$ (Lu et al, 2006). Room temperature methane detection was demonstrated for SWCNTs decorated with Pd clusters even at room temperarure and a few $\mathrm{mW}$ power consumption (Lu et al, 2004).

For multi-wall carbon nanotubes, a CR configuration has been studied (Meyyappan, 2005). In principle, the MWCNT based sensors must be less sensitive than those based on SWCNTs, as the measured current (and the associated noise) is supposed to pass through the whole volume of a MWCNT including all internal walls, whereas the reaction with gases should affect mainly the current fraction through the outermost wall. However, as discussed above, for distances shorter than $\sim 1 \mu \mathrm{m}$, current redistribution between graphitic shells is small (Moshkalev et al, 2008), i.e., for side contacted MWCNTs and short gaps between electrodes the major fraction of current passes through the outermost wall. In terms of sensing configuration, this effectively transforms a short side-contacted MWCNT in a bigdiameter "single-wall" metallic CNT, providing higher signal-to-noise ratio in gas sensing. Self-heating by Joule effect has been observed in nanotubes also, and so can be successfully employed in the case of CNTs based sensors, increasing sensitivity of hybrid CNT/NP systems to gases under interest, see below. Figure 3 shows some examples of MWCNTs decorated with $\mathrm{SnO}_{2}$ nanoparticles for sensing applications, and Fig. 4 presents an individual MWCNT and MWCNT film deposited over metal electrodes by DEP and decorated by $\mathrm{Ni}$ (electroless) and $\mathrm{SnO}_{2}$ (hydrolysis) nanoparticles, respectively.
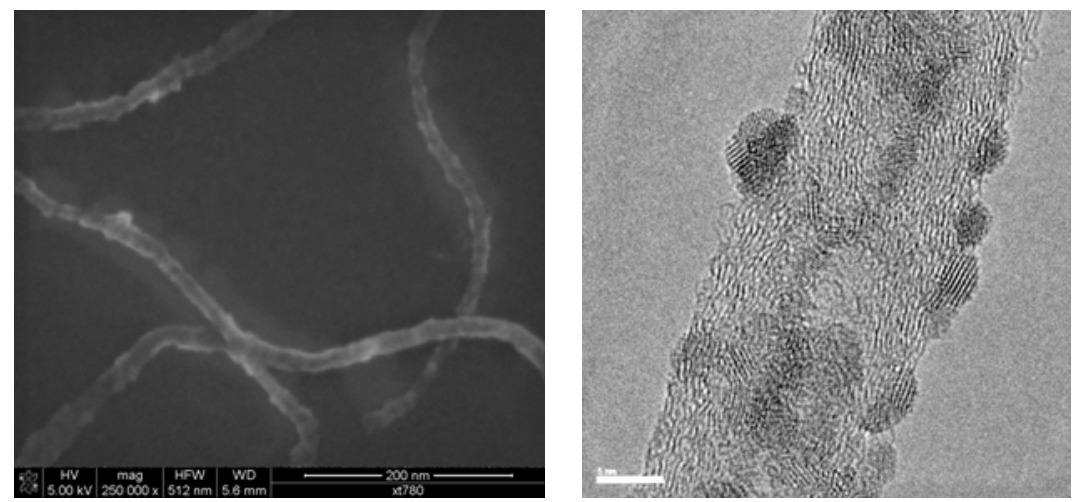

Fig. 3. SEM (left) and TEM (right) images of MWCNTs decorated by $\mathrm{SnO}_{2}$ nanoparticles.

Multi-wall carbon nanotubes decorated by Ti nanoparticles were used for gas $\left(\mathrm{N}_{2}, \mathrm{Ar}, \mathrm{O}_{2}\right)$ and pressure sensing at low temperatures (Gelamo et al, 2009). Chemiresistor sensor configurations with supported and suspended nanotubes were tested. For the latter, cuts between electrodes were produced by a focused ion beam before deposition of nanotubes by dielectrophoreris. 

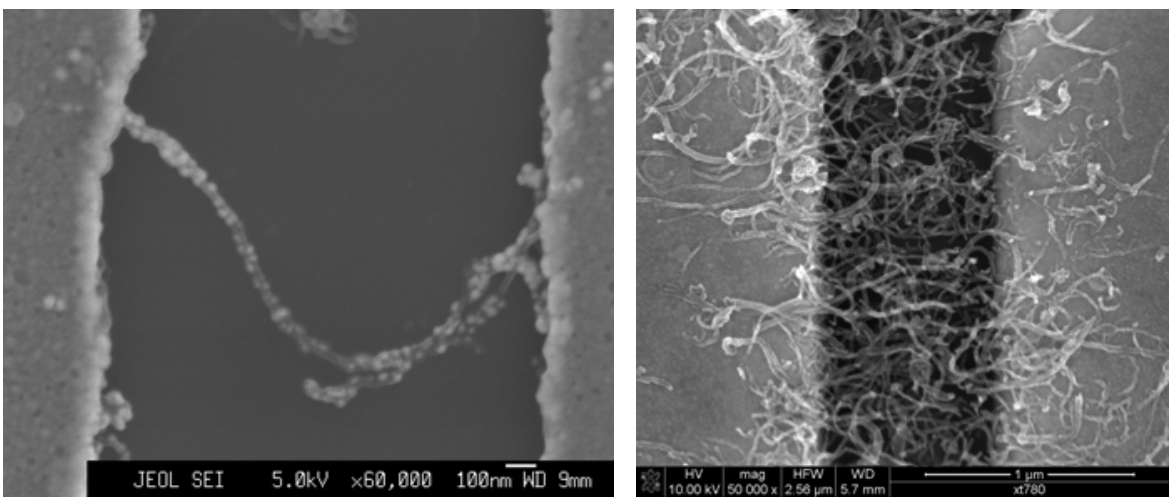

Fig. 4. Individual MWCNT (left) and MWCNT film (right) deposited over metal electrodes and decorated by $\mathrm{Ni}$ and $\mathrm{SnO}_{2}$ nanoparticles, respectively.

As can be seen in Fig. 5, two gas sensing mechanisms (chemical, for $\mathrm{O}_{2}$, and electrothermal, for chemically inert $\mathrm{Ar}$ and $\mathrm{N}_{2}$ ) were demonstrated. For the former, current decreases, and for the latter, increases during pulsed gas injection. The contributions of these mechanisms were shown to depend strongly on the CNT heat balance. The electrothermal mechanism is due to changes of the CNT electrical resistance (Kuo et al, 2007). Metallic MWCNTs can be self-heated considerably by current (in the way similar to NWs), and this leads to a rise of resistivity, with the temperature coefficient of resistivity $(\mathrm{TCR}) \sim 0.1 \% \mathrm{oC}^{-1}$ (Kawano et al, 2007). Further, when a gas is injected in the vacuum chamber, fast CNTs cooling by the gas may result in a measurable current increase. This effect was first observed by Kawano et al, 2007. For suspended nanotubes (and attached nanoparticles), heating by Joule effect is much stronger, resulting in strong enhancement of chemical sensitivity to gas (oxygen).

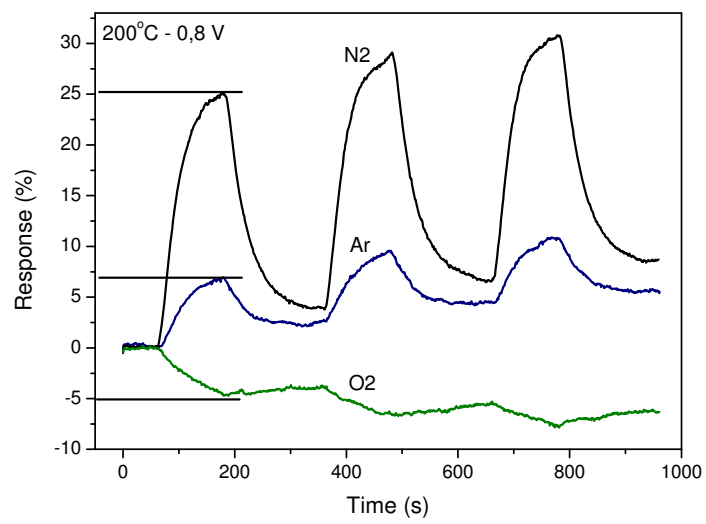

Fig. 5. Sensor response to pulses of gases $\mathrm{N}_{2}, \mathrm{Ar}$ and $\mathrm{O}_{2}$, peak pressures of 150, 30 and 4 mTorr, respectively (Gelamo et al, 2009).

Finally, a CNT/NP hybrid material has been successfully applied for low-pressure gas sensing applications in chemical resistor configuration. In this configuration, multi-wall 
carbon nanotubes serve as a conductive channel (for electrical signal acquisition), a heating element (for local heating of attached nanoparticles), and a substrate for NPs deposition (for selective gas sensitivity), whereas nanoparticles are employed to provide selective sensitivity to specific gases.

\section{Conclusion}

Many potential applications of carbon nanotubes in microelectronics are now being investigated extensively in many laboratories. Just a few specific applications are considered in the present work in more detail, showing some current problems and achievements. Some earlier expectations have failed, but many new opportunities arise constantly and, in many cases, unexpectedly. Recent introduction of new related nanocarbon material, graphene, is just one such example. For successful large-scale integration in new microdevices, development of reliable and compatible technologies that provide well controlled synthesis, positioning, characterization, manipulation and modification of nanotubes properties is still a great challenge.

\section{Acknowledgements}

The authors greatly acknowledge the contributions from Drs. J. Leon, A. R. Vaz, F. P. Rouxinol, A. Abbaspourad, and Mr. A. Flacker (CCS-UNICAMP), and financial support from CNPq, INCT-NAMITEC and FAPESP.

\section{References}

Akcoltekin, S.; Kharrazi, M. El ; Khler, B.; Lorke A. \& Schleberger, M. (2009). Graphene on insulating crystalline substrates. Nanotechnol., 20, (2009), 155601-6, ISSN 1361-6528

Berger, C., Song, Z., Li, T., Li, X., Ogbazghi, A.Y., Feng, R., Dai, Z., Alexei, N., Conrad, M.E.H., First, P.N., De Heer, W.A (2004). Ultrathin epitaxial graphite: 2D electron gas properties and a route toward graphene-based nanoelectronics, J. Phys. Chem B 108, 19912-19916 (2004). ISSN: 1520-6106

Bourlon, B.; Miko, C.; Forró, L.; Glatti, D.C. \& Bachtold, A. (2004). Determination of the intershell conductance in multiwalled carbon nanotubes. Phys. Rev. Lett., 93, (2004) 176806-4, ISSN 0031-9007

Castro Neto, A. H. ; Guinea, F.; Peres, N. M. R.; Novoselov, K. S. \& Geim, A. K. (2009). The electronic properties of graphene. Rev. Mod. Phys., 81, (2009), 109-162, ISSN 00346861, and references therein.

Chan, K. T.; Neaton, J. B. \& Cohen, M. L. (2008). First-principles study of metal adatom adsorption on graphene, Phys. Rev. B 77, (2008), 235430-12p., ISSN 0163-1829

Geim A. K. \& Novoselov, K. S. (2007). The rise of graphene. Nature Materials, 6, (2007), 183191, ISSN 1476-4660

Gelamo, R. V.; Rouxinol, F. P.; Veríssimo, C.; Vaz, A.R.; Bica de Moraes, M. A.; \& Moshkalev, S.A. (2009). Low-temperature gas and pressure sensor based on multiwall carbon nanotubes decorated with Ti nanoparticles. Chem. Phys. Lett., 482, 302306, ISSN 0009-2614 
Giovannetti, G.; Khomyakov, P. A.; Brocks, G.; Karplan, V. M. ; Brink, J. van den \& Kelly, P. J. (2008). Doping Graphene with Metal Contacts. Phys. Rev. Lett., 101, (2008), 268034, ISSN 0031-9007

Graham, A.P.; Duesberg, G.S.; Seidel, R.; Liebau, M.; Unger, E.; Kreupl, F. \& Honlein, W. (2004). Towards the integration of carbon nanotubes in microelectronics, Diam. Relat. Mater., 13, (2004) 1296-1300, ISSN 0925-9635

Ishigami, M.; Chen, J. H.; Cullen, W. G.; Fuhrer, M. S. \& Williams, E. D. (2007). Atomic structure of graphene on $\mathrm{SiO}_{2}$. Nano Lett., 7, (2007) 1643-1648, ISSN 1530-6992

Jackson, R. \& Graham, S. (2009). Specific contact resistance at metal/carbon nanotube interfaces, Appl. Phys. Lett., 94, (2009) 012109-3, ISSN 0003-6951

Jun, S.C., Choi, J.H., Cha, S.N., Baik, C.W., Lee, S., Kim, H.J., Hone, J. \& Kim, J.M. (2007). Radio-frequency transmission characteristics of a multi-walled carbon nanotube, Nanotechnol., 18, (2007) 255701-5, ISSN 1361-6528

Kawano, T.; Chiamori, H. C.; Suter, M.; Zhou, Q.; Sosnowchik, B. D. \& Lin, L. (2007). An electrothermal carbon nanotube gas sensor, Nano Lett., 7, (2007) 3686-3690, ISSN 1530-6992

Kim, B.-K. ; Park, N.; Na, P. S.; So, H.-M.; Kim, J.-J.; Kim, H.; Kong, K.-J.; Chang, H.; Ryu, B.H. ; Choi, Y. \& Lee, J.-O. (2006). The effect of metal cluster coatings on carbon nanotubes. Nanotechnol., 17, (2006) 496-500, ISSN 1361-6528

Kolmakov A. \& Moskovits, M. (2004). Chemical sensing and catalysis by one-dimensional metal-oxide nanostructures, Annu. Rev. Mater. Res., 34, (2004) 151-180, ISSN 00846600

Kong, J.; Chapline, M. G. \& Dai, H. (2001). Capillary force lithography. Adv. Mater., 13, (2001) 1386-1389, ISSN 0935-9648

Krupke, R. ; Hennrich, F.; Weber, H.B.; Beckmann, D.; Hampe, O.; Malik, S.; Kappes, M.M. \& Lohneysen, H.V. (2003). Contacting single bundles of carbon nanotubes with alternating electric fields, Appl. Phys. A, 76 (2003), 397-400, ISSN 1432-0630

Kuo, C. Y.; C. L. Chan, Gau, C.; Liu, C. W.; Shiau, S. H.; \& Ting, J. H. (2007). Nano temperature sensor using selective lateral growth of carbon nanotube between electrodes, IEEE Trans. Nanotech., 6, 1, (2007) 63-69, ISSN 1536-125X

Lan, C. ; Zakharov, D. N.; \& Reifenberger, R. G. (2008). Determining the optimal contact length for a metal/multiwalled carbon nanotube interconnect, Appl. Phys. Lett., 92, (2008), 213112-3p., ISSN 0003-6951

Liebau, M., Unger, E., Duesberg, G.S., Graham, A.P., Seidel, R., Kreupl, F. \& Hoenlein, W. (2003). Contact improvement of carbon nanotubes via electroless nickel deposition. Appl. Phys. A, 77, (2003) 731-734, ISSN 1432-0630

Liu, Z., Ci, L. ; Bajwa, N. ; Ajayan, P. M. ; \& Lu J.-Q. (2008). Benchmarking of Metal-toCarbon Nanotube Side Contact Resistance, Proc. of International Interconnect Technology Conference, IITC 2008, pp. 144-146, ISBN 978-1-4244-1911-1, June 2008, Burlingame, CA, USA, IEEE,

Lu, Y.; J. Li, Han, J.; Ng, H.-T.; Binder, C.; Partridge, C. \& Meyyappan, M. (2004). Room temperature methane detection using palladium loaded single-walled carbon nanotube sensors. Chem. Phys. Lett., 391, (2004) 344-348, ISSN 0009-2614

Lu, Y.; Partridge, C.; Meyyappan, M. \& Li, J. (2006). A carbon nanotube sensor array for sensitive gas discrimination using principal component analysis. J. Electroanalyt. Chem., 593, (2006) 105-110, ISSN 0018-8646 
Matsuda, Y.; Deng, W.-Q. \& Goddard III, W.A. (2007). Contact resistance properties between nanotubes and various metals from quantum mechanics. J. Phys. Chem C, 111, (2007) 11113-11116, ISSN 1932-7447

Meyyappan, M. (2005). Carbon nanotubes: science and applications. (CRC Press LLC, Florida, 2005). ISBN 978-0849321115

Moshkalev S. A. \& Veríssimo, C. (2007). Nucleation and growth of carbon nanotubes in catalytic chemical vapor deposition. J. Appl. Phys., 102, (2007) 044303-5.

Moshkalev, S.A. ; Leon, J. ; Verissimo, C. ; Vaz, A.R. ; Flacker, A. ; Moraes, M.B. de \& Swart, J. W. (2008). Controlled Deposition and Electrical Characterization of Multi-Wall Carbon Nanotubes, J. Nano Res., 3, (2008) 25-32, ISSN 1662-5260

Naeemi, A. \& Meindl, J.D. (2007). Carbon Nanotube Interconnects. Proc. of the 2007 Internat. Symp. Physical Design, ISPD'07., pp. 77-84, March 2007, Austin, Texas, USA. ISBN:978-1-59593-613-4

Novoselov, K. S. ; Geim, A. K. ; Morosov, S. V. ; Jiang, D. ; Zhang, Y. ; Dubonos, S. V. ; Grigorieva, I. V. \& Firsov, A. A. (2004). Electric field in atomically thin carbon films. Science, 306, (2004) 666-669, ISSN 1095-9203, and supporting on-line material.

Prades, J. D. ; Jimenez-Diaz, R. ; Hernandez-Ramirez, F. ; Barth, S. ; Cirera, A. ; RomanoRodriguez, A. ; Mathur, S. \& Morante, J. R. (2008). Ultralow power consumption gas sensors based on self-heated individual nanowires. Appl. Phys. Lett., 93, (2008) 123110-3, ISSN 0003-6951

Ran, Q. ; Gao, M. ; Guan, X. ; Wang, Y. \& Yu, Z. (2009). First-principles investigation on bonding formation and electronic structure of metal-graphene contacts. Appl. Phys. Lett., 94, (2009), 103511-3, ISSN 0003-6951

Sharma, P. \& Ahuja, P. (2008). Recent advances in carbon nanotube-based electronics. Mater. Res. Bull., 43, (2008) 2517-2526, ISSN 0025-5408

Star, A. ; Joshi, V. ; Skarupo, S. ; Thomas, D. \& Gabriel, J.C. (2006). Gas sensor array based on metal-decorated carbon nanotubes, J. Phys. Chem. B, 110, (2006) 21014-9, ISSN 1520-6106

Tan, C.W. \& J. Miao (2007). Transmission Line Characteristics of a CNT-based Vertical Interconnect Scheme. Proc. IEEE 57th Electronic Components \& Technology Conference, 1936-1941. ISBN: 9781424409846, , Sparks, Nevada, May 2007, IEEE

Vaz, A.R. ; Macchi, M. ; Leon, J. ; Moshkalev, S.A. ; \& Swart, J.W. (2008). Platinum thin films deposited on silicon oxide by focused ion beam: characterization and application, J. Mater. Sci., 43, (2008) 3429-3434, ISSN 1573-4803

Wang, X. ; Ouyang, Y. ; Li, X. ; Wang, H. ; Guo, J. \& Dai, H. (2008). Room-temperature allsemiconducting sub-10-nm graphene nanoribbon field-effect transistors. Phys. Rev. Lett. 100, (2008) 206803-4, ISSN 0031-9007

Zhao, L. ; Choi, M. ; Kim, H.-S. \& Hong, S.-H. (2007). The effect of multiwalled carbon nanotube doping on the $\mathrm{CO}$ gas sensitivity of $\mathrm{SnO}_{2}$-based nanomaterials. Nanotechnol., 18, (2007) 445501-5, ISSN 1361-6528

Zhou, S. Y. ; Gweon, G. -H. ; Fedorov, A. V. ; First, P. N. ; de Heer, W. A. ; Lee, D. -H. ; Guinea, F. ; Castro Neto, A. H. \& Lanzara, A. (2007). Substrate-induced bandgap opening in epitaxial graphene. Nature Materials, 6, (2007), 770-775, ISSN 1476-4660 


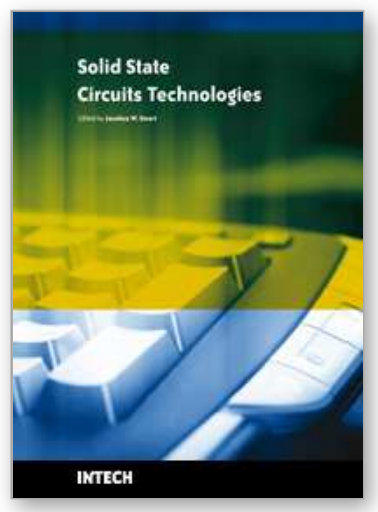

\author{
Solid State Circuits Technologies \\ Edited by Jacobus W. Swart
}

ISBN 978-953-307-045-2

Hard cover, 462 pages

Publisher InTech

Published online 01, January, 2010

Published in print edition January, 2010

The evolution of solid-state circuit technology has a long history within a relatively short period of time. This technology has lead to the modern information society that connects us and tools, a large market, and many types of products and applications. The solid-state circuit technology continuously evolves via breakthroughs and improvements every year. This book is devoted to review and present novel approaches for some of the main issues involved in this exciting and vigorous technology. The book is composed of 22 chapters, written by authors coming from 30 different institutions located in 12 different countries throughout the Americas, Asia and Europe. Thus, reflecting the wide international contribution to the book. The broad range of subjects presented in the book offers a general overview of the main issues in modern solid-state circuit technology. Furthermore, the book offers an in depth analysis on specific subjects for specialists. We believe the book is of great scientific and educational value for many readers. I am profoundly indebted to the support provided by all of those involved in the work. First and foremost I would like to acknowledge and thank the authors who worked hard and generously agreed to share their results and knowledge. Second I would like to express my gratitude to the Intech team that invited me to edit the book and give me their full support and a fruitful experience while working together to combine this book.

\title{
How to reference
}

In order to correctly reference this scholarly work, feel free to copy and paste the following:

Stanislav A. Moshkalev, Carla Veríssimo, Rogério V. Gelamo, Leonardo R. C. Fonseca, Ettore Baldini-Neto and Jacobus W. Swart (2010). Integration of Carbon Nanotubes in Microelectronics, Solid State Circuits Technologies, Jacobus W. Swart (Ed.), ISBN: 978-953-307-045-2, InTech, Available from: http://www.intechopen.com/books/solid-state-circuits-technologies/integration-of-carbon-nanotubes-inmicroelectronics

\section{INTECH}

open science | open minds

\section{InTech Europe}

University Campus STeP Ri

Slavka Krautzeka 83/A

51000 Rijeka, Croatia

Phone: +385 (51) 770447

Fax: +385 (51) 686166

\section{InTech China}

Unit 405, Office Block, Hotel Equatorial Shanghai

No.65, Yan An Road (West), Shanghai, 200040, China 中国上海市延安西路65号上海国际贵都大饭店办公楼 405 单元

Phone: +86-21-62489820

Fax: +86-21-62489821 
www.intechopen.com 
(C) 2010 The Author(s). Licensee IntechOpen. This chapter is distributed under the terms of the Creative Commons Attribution-NonCommercialShareAlike-3.0 License, which permits use, distribution and reproduction for non-commercial purposes, provided the original is properly cited and derivative works building on this content are distributed under the same license. 